University for Business and Technology in Kosovo

UBT Knowledge Center

UBT International Conference

2017 UBT International Conference

Oct 27th, 3:00 PM - 4:30 PM

\title{
Applying a Revised Approach of Fuzzy Cognitive Maps on a Hybrid Electrical Energy System
}

\author{
Ekavi Antoniou \\ University of Patras, eantoniou@oxygenbroadband.gr \\ Eleni S. Vergini \\ University of Patras \\ Peter P. Groumpos \\ University of Patras, groumpos@ece.upatras.gr
}

Follow this and additional works at: https://knowledgecenter.ubt-uni.net/conference

Part of the Bioresource and Agricultural Engineering Commons

\section{Recommended Citation}

Antoniou, Ekavi; Vergini, Eleni S.; and Groumpos, Peter P., "Applying a Revised Approach of Fuzzy Cognitive Maps on a Hybrid Electrical Energy System" (2017). UBT International Conference. 137.

https://knowledgecenter.ubt-uni.net/conference/2017/all-events/137

This Event is brought to you for free and open access by the Publication and Journals at UBT Knowledge Center. It has been accepted for inclusion in UBT International Conference by an authorized administrator of UBT Knowledge Center. For more information, please contact knowledge.center@ubt-uni.net. 


\title{
Applying a Revised Approach of Fuzzy Cognitive Maps on a Hybrid Electrical Energy System
}

\author{
Ekavi Antoniou ${ }^{1}$, Eleni S. Vergini ${ }^{2}$ and Peter P. Groumpos ${ }^{2}$ \\ ${ }^{1}$ Departement of Electrical and Computer Engineering, University of Patras, Rion \\ 26500, Greece, eantoniou@ oxygenbroadband.gr \\ 2,3 Departement of Electrical and Computer Engineering, University of Patras, Rion \\ 26500, Greece
}

\begin{abstract}
Complex systems modeling is a rapidly developing research field which incorporates various scientific sectors. However, as the systems' complexity increases pure mathematical modeling techniques prove to be a rather laborious task which demands wasting many resources and in many occasions, could not lead to the desired system response. This realization led towards the evolution of computational intelligence, Neural Networks, Fuzzy Logic etc.

FCM came as a combination of Neural Networks and Fuzzy Logic. All these years they have been applied on a variety of systems such as social, psychological, medical, agricultural, marketing, business management, energy, advertising etc, both for systems modeling and decision-making support systems, with very promising results. Based on the experts' knowledge, the interrelations among the system variables are determined and the system response is defined. Through years, improvements have been made and learning algorithms were embodied to the initial approach. However, all these decades, researchers have mentioned some weak points as well. In the last years substantial research has been made in order to overcome some of the wellknown limitations of the FCM methodology.

This paper will apply a revised approach of the Fuzzy Cognitive Maps method on a technoeconomic study of an autonomous hybrid system photovoltaic and geothermal energy The aim of the study is to provide maximum performance with the minimum total cost. Computational Intelligence and especially Fuzzy Cognitive Maps are a very promising field in modeling complex systems. The latest approaches of the method show that FCM can open new paths towards higher efficiency, more accurate models and effective decision-making results.
\end{abstract}

Keywords: Fuzzy Cognitive Maps, Hybrid Energy System, System Modeling.

\section{Introduction}

In recent decades, along with the computer science evolution, systems modeling and control have led to innovative applications regarding various scientific fields such as social, psychological, medical, agricultural, marketing, business management, energy, advertising etc.

Cognitive Maps were firstly introduced by R. Axelrod in 1976, as a formal way of representing social scientific knowledge and modeling decision in social and political systems [1]. Since then, Cognitive Maps have been applied in a number of different scientific areas.

In 1986, Kosko introduced a soft computing methodology as an extension of Cognitive Maps and named it Fuzzy Cognitive Maps (FCM) [2]. Combining the reasoning of Fuzzy Logic and the system approach of Artificial Neural Networks (ANN), FCMs are a modeling method which has been under research during the last decades and they have been applied in modeling various systems, giving very promising results. Learning Algorithms, being an important part in the training procedure of ANNs, were also applied on FCMs, improving their response. There is a 
variety of algorithms which were developed, some of them are based on the initial Hebbian Algorithm ([3]) and some of them based on the Generic Algorithms and many others ([4]). Learning Algorithms usually use historical data in order to appropriately train the system and avoid the need of human intervention. In addition, they contribute to the achievement of dynamical system response, which is very important especially in the case of complex systems.

\section{Fuzzy Cognitive Maps}

\section{Classical Theory}

FCMs became popular because they are very simple and close to human reasoning. These systems have many parameters and also they are difficult to model using a mathematical approach. For that reason, FCMs are considered to be appropriate to solve complex problems without using complex mathematics. On the other hand, they are based on experts' opinion and their human decision making approach of problems.

Combining the theory of both Neural Networks and Fuzzy Logic, FCMs use a graph to represent a given system as a collection of concepts and the interrelations between them. They are usually assorted as neuro-fuzzy systems and they are competent to incorporate and adapt human knowledge. In a simple FCM graph, as it is shown in Fig.1, the system variables are defined by experts, and each one of them is considered to be a concept (A1, A2, etc). Concepts take values in the interval $[0,1]$. The interconnection between two concepts (for example Ai and $\mathrm{Aj}$ ) is called weight (wji) and it is defined by taking a value in interval $[-1,+1]$.

- If wji<0 then there is a negative interrelation between concepts Ai and Aj. This means that an increase of the Aj value will cause a decrease of Ai value.

- If wji>0 then there is a positive interrelation between concepts Ai and Aj. This means that an increase of the Aj value will cause an increase of Ai value.

- If wji=0 then there is not any interrelation between concepts Ai and Aj. This means that their values are in dependent to each other.

The absolute value of each weight signifies the level of influence between the two concepts. Apart from a graph representation, a FCM can be determined by a square matrix, which is called "Weight Matrix". The weight between two concepts is set in their corresponding cell. 


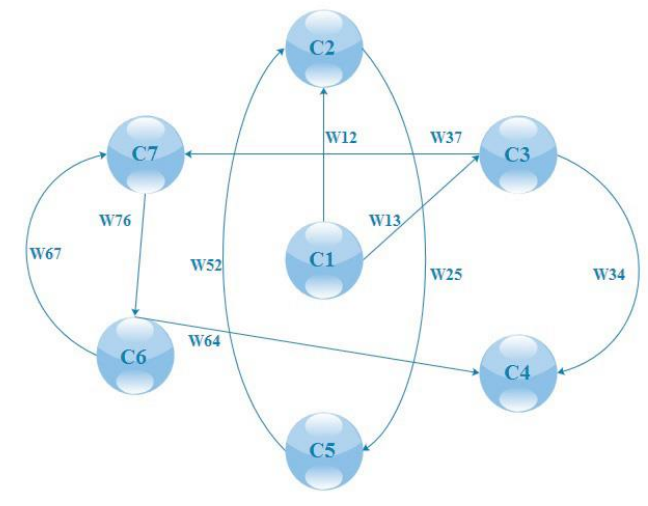

Fig.6. A basic FCM graph.

During simulation, the value of each concept is calculated using the following rule:

$$
A_{i}[k+1]=f\left(A_{i}[k]+\sum_{j=1, j \neq 1}^{n}\left(A_{j}[k] w_{j i}\right)\right)
$$

Where $k$ represents the iteration number, $n$ is the number of concepts and $f$ is the sigmoid function given by the following equation:

$$
f(x)=\frac{1}{1+\mathrm{e}^{-\lambda x}}
$$

In which $\lambda>0$ determines the steepness of function $f$.

Based on neural networks, FCMs have a non-linear structure. The algorithm of non-linear Hebbian learning uses a learning rate parameter $\eta_{\kappa}$ and a weight decay parameter $\gamma$, in order to calculate updated weight values, changing only non-zero weights that experts initially gave, and then the concept values are updated. The non-linear Hebbian learning algorithm is based on equation (3):

$$
W_{j i}^{(k+1)}=\gamma W_{j i}^{k}+\eta A_{i}^{k}\left[A_{j}^{k}-\operatorname{sign}\left(w_{j i}^{k}\right)\right] W_{j i}^{k} A_{i}^{k}
$$

\section{FCMs Revised Approach}

Applying the FCMs method in complex systems and in various applications, their advantages were confirmed and also some weak points were brought to light, leaving space for further 
research and improvement. Mpelogianni and Groumpos in [5] have been presenting a new approach regarding three parts, the concepts calculation equation, the sigmoid function and the learning algorithm. This approach has been implemented on the model of a Hybrid Electrical Energy System, as it will be discussed in section 3.

The proposed equation uses the total variation which is caused in concept Ai by all other concepts and it is described by equation (4).

$$
A_{i}[k+1]=f\left(A_{i}[k]+\frac{\sum_{j=1, j \neq 1}^{n} A_{j}[k] w_{j i}}{\sum_{j=1, j \neq 1}^{n} w_{j i}}\right)
$$

Regarding the sigmoid function, equation (5) was used in order to have the opportunity to apply sigmoid functions with different slopes, upper limit, lower limit and symmetry to the y axis.

$$
f(x)=m+\frac{M-m}{1+e^{(-r(x-t o))}}
$$

Where:

- $\quad M$ : upper limit of function $f$

- $\quad m$ : lower limit of function $f$

- $\quad r$ : slope of the curve

- $t 0$ : symmetry to y axis

As it was mentioned above learning algorithms are used in order to change the weight values and achieve a better system response. In order to keep the correct weight sign, and as a consequence the correct causality, the NHL equation was slightly changed, as it is presented in equation (6).

(6)

$$
W_{j i}^{(k+1)}=\operatorname{sign}\left(W_{j i}\right)^{k}\left[\gamma\left|W_{j i}^{k}\right|+\eta A_{i}^{k}\left[A_{j}^{k}-\operatorname{sign}\left(w_{j i}^{k}\right)\right] W_{j i}^{k} A_{i}^{k}\right] \quad \text { In the }
$$

following section all the above parts will be applied on a hybrid electrical energy system. The results will be discussed leaving place for further investigation and research.

\section{Application on a Hybrid Electrical System}

The FCM which was created consists of twenty-seven concepts describing the variables of a hybrid electrical system. This system includes a photovoltaic array, a geothermal energy production unit, batteries and o control unit system. More specifically:

- $\quad$ C1 : PV Array Material

- $\quad \mathrm{C} 2$ : PV Array Age

- $\quad$ C3 : PV Angle
- $\quad$ C15 : Geothermal power

- C16 : Ground temperature and pressure

- $\quad$ C17 : Geothermal energy loss 
- $\quad$ C4 : Solar Radiation

- $\quad$ C5 : PV Array Efficiency

- C6 : Cell Temperature

- $\quad$ C7 : PV Power

- $\quad$ C8 : Environmental Temperature

- $\quad$ C9 : Day of the year

- $\mathrm{C} 10: \mathrm{PV}$ ratio in the total system

- $\quad$ C11 : PV array cost

- $\mathrm{C} 12$ : Temperature and pressure of geothermal liquid

- $\quad$ C13 : Geothermal energy usage ratio

- $\mathrm{C} 14$ : Intermediate pressure
- C18 : Geothermal unit ratio in the total system

- C19: Geothermal unit cost

- $\quad$ C20 : Battery size

- $\quad \mathrm{C} 21$ : Battery replacement cost

- $\mathrm{C} 22$ : Battery efficiency

- $\quad$ C23 : Power consumption of control unit

- $\quad$ C24 : Control unit cost

- C25 : Total efficiency

- C26 : Total electrical power

- $\quad$ C27 : Total cost

The weight matrix describing the interrelations among concepts is a $27 \times 27$ matrix. Concepts $\mathrm{C} 25$, C26 and C27 are the FCM output concepts although in this paper only the total efficiency output will be discussed. The results which were achieved regarding the total efficiency output are presented in Fig.2, Fig.3 and Fig.4.

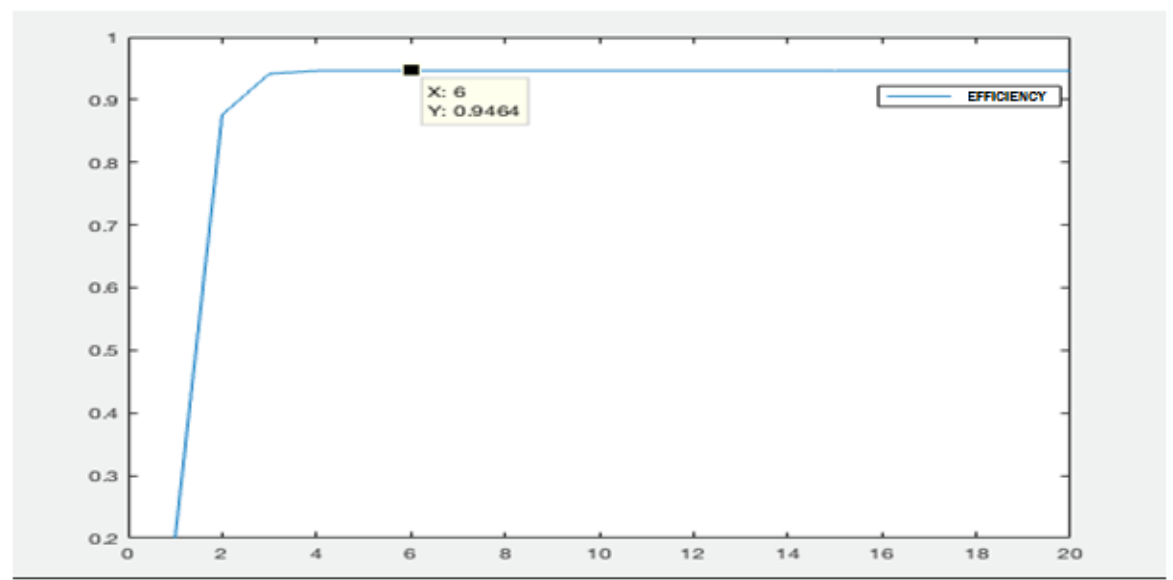

Fig.2 Total efficiency using the proposed sigmoid function $f$

Final value 0.9464 


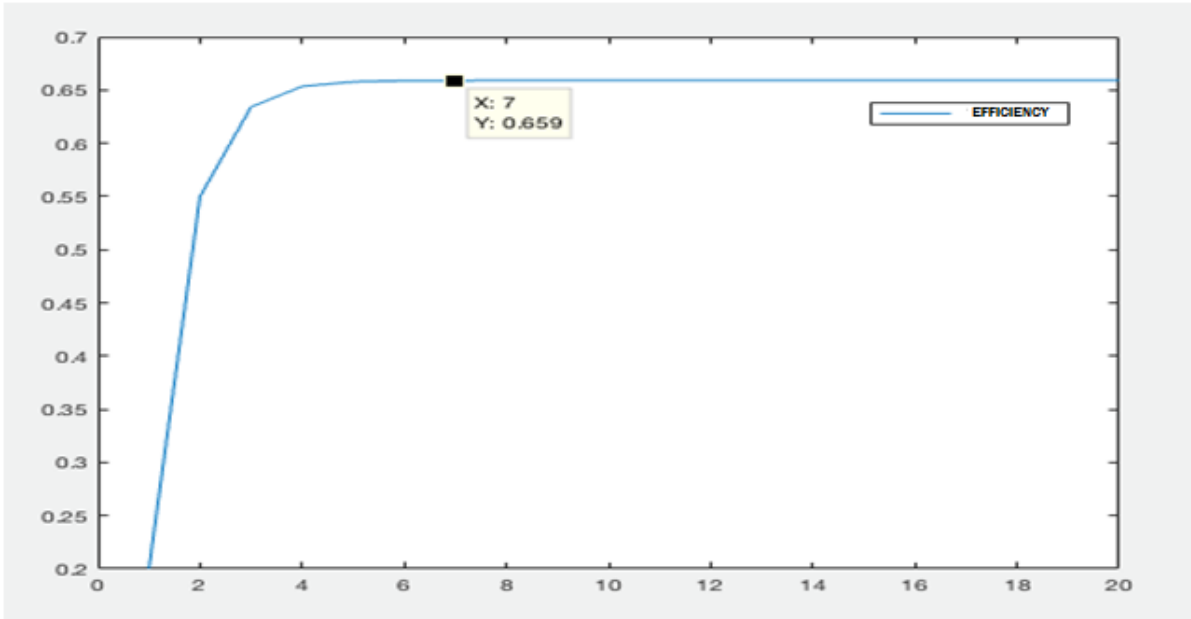

Fig.3 Total efficiency using the proposed concept calculation equation

Final value 0.659

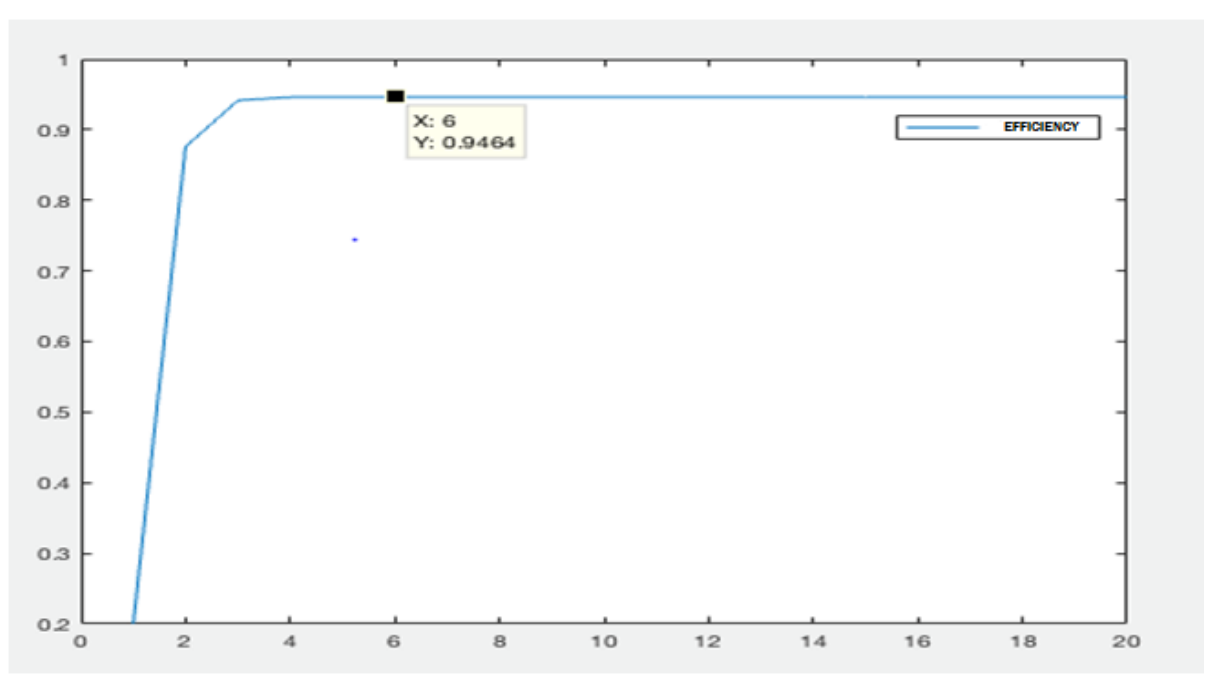

Fig.4 Total efficiency using the proposed learning algorithm equation

Final value 0.9464

In all cases, applying the new approach the system response is steady and it reaches an equilibrium point. In the case of the new equation (Fig.3) the result is quite lower than the others (final value 0.659 ). This happens because the new equation calculates the total change that all other concepts will cause to the total efficiency and then it adds the sum. Another point that should be mentioned is the fact that although the system is complex (27 concepts) the number of iterations is low. The system reaches its final value in five or six iterations making the procedure easy and without the necessity of high computational resources and time. 


\section{Conclusions and Future Research}

FCMs, researched and approached by scientists all over the world, are a powerful method, especially in the case of complex systems, which need difficult mathematic approach and higher level computational power. Of course the weak points of this method are in the front line right now for researchers, giving the opportunity to open the horizons increasing their efficiency, applying them in complex systems and giving an alternative solution to difficult and highly demanding problems.

\section{References}

1. Axelrod,R.(1976).The analysis of cognitive maps. Structure of decision, 55-73.

2. Kosko,B.(1986).Fuzzy cognitive maps. International Journal of man-machine studies, 24(1), 65-75.

3. Papageorgiou E., Stylios C. and Groumpos P. (2003). Fuzzy cognitive map learning based on non linear Hebbian rule. In Australasian Joint Conference on Artificial Intelligence, 256-268. Springer

4. Papageorgiou E.I. (2012). Learning algorithms for fuzzy cognitive maps a review study. IEEE Transactions on Systems, Man, and Cybernetics, Part C (Applications and Reviews), 42(2), 150-163.

5. V.Mpelogianni and P.P.Groumpos, "A revised approach in modeling fuzzy cognitive maps", in Control and Automation (MED), $201624^{\text {th }}$ Mediterranean Conference on IEEE, 2016, pp. 350-354.

6. Peter Jansohn. Modern gas turbine systems: High efficiency, low emission, fuel flexible power generation. Woodhead publishing, 2013.

7. http://siteresources.worldbank.org/KOSOVOEXTN/Resources/2977691329940905064/kosovo_slideshow.pdf.

8. Rolf Kehlhofer, Frank Hannemann, Franz Stirnimann, i Bert Rukes. Combined-Cycle Gas Steam Turbine Power Plants. Longman Group Limited, 4. izdanje, 1996.

9. https://www.treehugger.com/wind-technology/future-wind-power-9-coolinnovations.html. 